\title{
BMJ Open Prevalence of smoking, quit attempts and access to cessation treatment among adults with mental illness in Brazil: a cross-sectional analysis of a National Health Survey
}

\author{
Erica Cruvinel (D) , ${ }^{1}$ Edward Liebman, ${ }^{1}$ Isabel Leite, ${ }^{2}$ Jinxiang $\mathrm{Hu},{ }^{3}$ \\ Kimber P Richter ${ }^{1}$
}

To cite: Cruvinel E, Liebman E, Leite I, et al. Prevalence of smoking, quit attempts and access to cessation treatment among adults with mental illness in Brazil: a crosssectional analysis of a National Health Survey. BMJ Open 2020;10:e033959. doi:10.1136/ bmjopen-2019-033959

- Prepublication history and additional material for this paper are available online. To view these files, please visit the journal online (http://dx.doi org/10.1136/bmjopen-2019033959).

Received 02 September 2019 Revised 18 March 2020 Accepted 01 May 2020

Check for updates

(c) Author(s) (or their employer(s)) 2020. Re-use permitted under CC BY-NC. No commercial re-use. See rights and permissions. Published by BMJ.

${ }^{1}$ Department of Population Health, University of Kansas Medical Center, Kansas City, Kansas, USA

${ }^{2}$ School of Medicine, Federal University of Juiz de Fora, Juiz de Fora, MG, Brazil

${ }^{3}$ Department of Biostatistics, University of Kansas Medical Center, Kansas City, Kansas, USA

Correspondence to

Dr Erica Cruvinel;

ericacruvinel@gmail.com

\section{ABSTRACT}

Objectives Determine the national prevalence of smoking and factors related to smoking among adults with mental illness (PLWMI; people living with mental illness) in Brazil. Design Cross-sectional study.

Setting We used data from the nationally representative general health survey Pesquisa Nacional de Saude of 2013, which included the Global Adult Tobacco Survey (GATS) module.

Participants The survey used a complex probabilistic sample to collect data from 60202 Brazilians 18 years or older. Primary and secondary outcomes: smoking prevalence and access to smoking cessation treatment. We also assessed past tobacco use, quit attempts and quit ratio among people with and without mental illness. Analyses were conducted in $\mathrm{R}$ and were weighted to account for the survey design and generate national estimates.

Results In Brazil, the 2013 smoking prevalence among PLWMI was $28.4 \%$ and among people with no mental illness was $12.8 \%$. Both groups had high rates of pastyear quit attempts (51.6\% vs $55.3 \%$ ) but the lifetime quit ratio among PLWMI was much lower than those with no mental illness ( $37 \%$ vs $54 \%$ ). Adjusted odds showed PLWMI were more likely to be current smokers $(\mathrm{OR}(95 \% \mathrm{Cl})=2.60$ (2.40 to 2.82), less likely to be former smokers $(\mathrm{OR}(95 \% \mathrm{Cl})=0.62(0.55$ to 0.70$))$ and as likely to have tried to quit in the past year $(0 \mathrm{R}(95 \% \mathrm{Cl})=0.90(0.78$ to 1.02$)$ ). Very few (3.7\%) PLWMI and fewer with no mental illness $(2.6 \%)$ received cessation treatment.

Conclusion Smoking rates among PLWMI are roughly double the rate in the general population. Compared with Brazilian smokers without mental illness, those with mental illness were significantly less likely to quit even though as many tried to. Few Brazilians appear to be using publicly available cessation services. Expanding utilisation of treatment might be a good place to start for Brazil to further decrease the prevalence of smoking among PLWMI.

\section{INTRODUCTION}

Globally, over 1 billion people use tobacco and most tobacco users live in low-income and middle-income countries. ${ }^{1}$ Brazil, though
Strengths and limitations of this study

- This study provides the first national estimates, based on a representative sample, of the epidemic of tobacco use among people living with mental illness (PLWMI) in a middle-income country.

- PLWMI are twice as likely to smoke as those without mental illness and their quit ratio (the proportion of former to ever smokers), is much lower than those without mental illness.

- Most smokers, regardless of their mental health status, did not use evidence-based care freely available through the national health system.

- Similar to many national surveys, mental health status was identified through self-report measures that may result in under-reporting.

a middle-income country, is a world leader in comprehensive tobacco control and has achieved a dramatic decline in smoking rates, from a population prevalence of $34.8 \%$ in 1989 to $15 \%$ in $2014 .^{2}$ To do so, Brazil implemented numerous tobacco control policies including smoke-free air laws, marketing restrictions, graphic health warnings on cigarette packaging, national smoking cessation campaigns through the mass media, cigarette price increases and a national smoking cessation treatment programme. ${ }^{3}$ Despite these advances, 21.9 million tobacco users remain, ${ }^{4}$ and in 2015 Brazil was listed among the top 10 countries with the largest number of total smokers. ${ }^{2}$

As smoking prevalence drops in the general population, it becomes concentrated in groups experiencing social and economic disadvantage. ${ }^{5}$ To further drive down smoking prevalence, countries can direct treatment efforts to high prevalence subgroups that have been untouched by campaigns for 
the general public. ${ }^{6}$ Some advanced economy countries, notably Australia, the USA, the UK and Canada, have identified that people living with mental illnesses (PLWMI), including substance use disorders, have very high rates of tobacco use. ${ }^{7-9}$ For example, compared with the general population in the USA, smoking is more than three times as prevalent among those with schizophrenia, and twice as prevalent among Americans with bipolar disorder. ${ }^{10}$ Almost half of Americans with heavy alcohol use are current smokers. ${ }^{11}$

Helping PLWMI quit smoking is socially just, evidencebased, and will help with recovery from mental illness. PLWMI die on average 8 to 25 years prematurely. ${ }^{12-14}$ Tobacco use is causally linked to approximately half of the deaths in Americans who had been hospitalised for schizophrenia, bipolar disorder or major depressive disorder. ${ }^{15}$ Tobacco dependence treatment, including medications and behavioural support, is effective among PLWMI. ${ }^{16-19}$ Quitting smoking, moreover, is significantly associated with decreased anxiety, depression and stress as well as an improvement in overall mood and quality of life $^{2021}$ and is also associated with an increased likelihood of sobriety from alcohol and drugs. ${ }^{20} 22$

Brazil could further reduce tobacco prevalence by increasing cessation among PLWMI. Brazil's public universal healthcare system, 'Sistema Único de Saúde (SUS) ', was specifically designed to eliminate health status and health service disparities through a tiered system that includes community-based primary care, speciality and outpatient care and hospitals. ${ }^{23}$ With respect to smoking cessation, providers must undergo training to prescribe cessation medications and lead cessation groups, which use cognitive behavioural therapy. ${ }^{24}{ }^{25}$ Cessation services are for the most part provided through primary care. ${ }^{25}$ Mental health services, however, are primarily provided through Psychosocial Care Centres 'Centros de Atenção Psicossocial (CAPS)' and Centres for alcohol and drug use 'Centros de Atenção Psicossocial Álcool e Drogas (CAPS-AD)'.

Except for a few descriptive studies, tobacco use among people with mental and substance use disorders remains a hidden and unaddressed epidemic in Brazil. A survey in a single city estimated daily cigarette use at $59.9 \%$ among persons with severe mental illness. ${ }^{26}$ A cross-sectional study of 2475 patients in 26 mental health facilities found that $52.7 \%$ smoked and $80 \%$ smoked inside their mental health facility. ${ }^{27}$ Several small-scale observational studies suggest patients with mental illness adhere to tobacco treatment and have promising cessation outcomes. ${ }^{28} 29$ When offered training in how to treat tobacco dependence, however, clinicians in 17 facilities were resistant to treating tobacco dependence. ${ }^{30}$

Definitive, nationwide estimates of the distribution and determinants of tobacco use among PLWMI could help to guide tobacco control policies in Brazil. The purpose of this study was to determine the national prevalence of smoking among PLWMI in Brazil. We further sought to describe factors related to (a) smoking, (b) trying to quit and (c) successfully quitting, and to examine the extent to which people trying to quit used universally available cessation services to do so. These findings should depict health status and service disparities for this high prevalence population and help leverage resources to close these gaps and further drive down the prevalence and consequences of tobacco use in Brazil.

\section{METHODS}

\section{Data}

We used data from the nationally representative Brazilian National Health Survey 'Pesquisa Nacional de Saúde PNS' that is publicly available at http://asdfree.com. ${ }^{4}$ Its purpose is to produce population estimates of health status, chronic disease, health behaviour and use of health services. Data are collected via in-person individual interviews among adults aged 18 years and above. The survey uses a complex probabilistic sample with four selection stages (municipalities, census tracts, households and individuals aged 18 years and above). ${ }^{4}$ The PNS includes a short version of the Global Adult Tobacco Survey (GATSBrazil), which is part of the Global Tobacco Surveillance System established by the WHO to track the evolution of tobacco use. ${ }^{3}$ The most recent survey was conducted in 2013. ${ }^{4}$ A total of 62986 households were sampled, excluding 18781 vacant/non-existent household units and refusals. Only one individual per household was selected to answer questions about tobacco use, other risk factors for chronic diseases and morbidity. More information on the sampling procedures and survey administration for the PNS and GATS-Brazil are available. ${ }^{31}$ The PNS data is de-identified; the analysis presented in this manuscript did not require ethical approval as it was deemed to not constitute human subjects research.

\section{Variables}

\section{Socio-demographic measures}

We included social and demographic factors that are known to be robust determinants of tobacco use, including age, sex, race, education, ${ }^{32}$ employment $^{33}$ and private health insurance. ${ }^{34}$ The PNS uses race categories specific to Brazil that include self-identification as Branca (White), Preta (Black), Parda (Greyish/Brown), Amarela (Yellow) or Indígena (Indigenous). ${ }^{4}$ Participants had to report just one race. Categories for highest level of education completed were ' 0 to 7 years and $\geq 8$ '. This cut-point aligns with the national benchmark and priority of increasing the proportion of individuals who have at least 8 years of education. ${ }^{35}$ Employment status was assessed by through a question asking if the subject had a remunerated job in the last month, with a 'yes' or 'no' response option. The question "Compared with persons of your age, in general, how do you rate your own health status?" was used to assess self-rated health status, and categorised as 'very good', 'good', 'fair', 'poor' or 'very poor'. We collapsed these categories to 'very good/good' versus 'fair/poor/very poor' ${ }^{36}{ }^{37}$ The 
question to assess private health insurance coverage was "Do you have any kind of private health insurance or dental medical insurance provided by your employer or by your own individual plans?" with a 'yes' or 'no' response option.

\section{Mental illness}

To assess mental illness, the PNS asks respondents if a physician or other health professional had diagnosed the respondent with depression, schizophrenia, bipolar disorder, obsessive compulsive disorder (OCD) or any other mental illness. Participants could answer 'Yes' for more than one diagnosis. The PNS collected data related to hazardous drinking as defined by the Alcohol Use Disorders Identification Test (AUDIT) survey items and scoring system. ${ }^{38}$ Participants were asked how many alcoholic drinks they usually consumed on a typical day, and were asked if they engaged in binge drinking in the past 30 days. Respondents who consumed three or more drinks per day, and/or who engaged in the past 30 days binge drinking, were classified as hazardous drinkers.

\section{Tobacco use}

The GATS-Brazil section of the PNS asked all respondents to report if they currently smoked tobacco. Response options included 'daily', 'less than daily' or 'do not currently smoke'. The survey also asked if respondents had smoked in the past. We included as current smokers those who reported daily smoking, non-daily smoking and those who had quit less than a year. Past-year quit attempts was assessed among all current smokers. In order to calculate the population quit ratio (see below) we combined current and former smokers to 'ever smokers'.

Several items were administered only to persons who were smoking at the time of the interview, excluding persons who had recently quit. These included the type of tobacco smoked; options included 'manufactured', 'rolled by hand', 'clove cigarettes', 'pipes', 'cigars', 'hookah' and 'other'. In addition, daily smokers were asked to name the average number of manufactured cigarettes they smoked per day (CPD).

\section{Healthcare utilisation and seeking help for smoking cessation}

The PNS question "When was the last time that you saw a doctor?" was used to assess whether the respondent had a medical appointment in the past year. The question "In the past 12 months, how often did you receive a visit from a community health worker or from a member of the Family Health team?" was used to assess contact with community health workers in the past year. The dichotomous question "Did you seek the help of a health professional when you tried to quit smoking?" (Yes/No) was asked to smokers who have tried to quit in the past year and also among smokers who had quit for less than a year. An additional question was asked of smokers who answered 'Yes', inquiring if they actually received the treatment.

\section{Statistical analysis}

All analyses were weighted to account for the complex survey design of the PNS and were conducted in $\mathrm{R}^{39}$ V.3.3.1 using the 'survey' package. ${ }^{40} \chi^{2}$ tests using the Rao-Scott adjustment were used to assess associations between categorical variables. Independent samples t-tests were used to assess mean differences across groups. First, we described the prevalence of mental illnesses by calculating weighted percentages and $95 \%$ CIs. Next, we described the socio-demographic characteristics and the health status of people with and without mental illness in Brazil (table 1). Then, we used weighted percentages with $95 \%$ CIs, to compare smoking prevalence, past use of tobacco and quit attempts among people with and without any mental illness and with specific diagnoses (table 2). The quit ratio, figure 1 , is a valuable measure of total cessation in a population and was calculated as the percentage of former to ever smokers (quit ratio=former/ever smoker's $\times 100) .{ }^{41}$

The association between the number of cigarettes used per day (CPD) and the number of mental health diagnoses was evaluated by a $\chi 2$ test of association (figure 2 ). We organised the CPD score in three categories: up to $9(\leq 9)$ cigarettes, 10 to 19 and 20 or more $(\geq 20)$. We included non-daily smokers in the lowest tobacco use category $(\leq 9 \mathrm{CPD})$. The number of mental illness were grouped into three categories (none, one and two or more diagnoses).

The magnitude of the associations of having any mental illness with being a current smoker, being a former smoker and trying to quit in the past year was measured using ORs; 95\% CIs were obtained by logistic regression (table 3 ). The analysis was adjusted for potential confounders-in this case, socio-demographic variables (sex, age, education), health status and access to the health system.

We used weighted percentages with $95 \%$ CIs to compare quit attempts, access to smoking cessation treatment, type of tobacco product used and CPD among smokers with and without mental illness (table 4). The analysis of the type of tobacco products included only current smokers $(n=8729)$. Quit attempts were measured among current smokers and smokers that had quit less than a year $(n=9912)$. Quit assistance includes current smokers who tried to quit in the past year and former smokers who quit less than a year $(n=4672)$. CPD includes only current smokers of manufactured cigarettes $(n=6110)$.

\section{Patient and public involvement}

Patients and or public were not involved in this study. There are no plans to disseminate the research results to study participants.

\section{RESULTS}

\section{Study sample}

The reporting of this study conforms to the Strengthening the Reporting of Observational Studies in Epidemiology 
Table 1 Characteristics of people living with and without mental illness in Brazil, 2013

\begin{tabular}{|c|c|c|c|c|c|}
\hline \multirow[b]{2}{*}{ Variables } & \multicolumn{2}{|c|}{ Any mental illness } & \multicolumn{2}{|c|}{ No mental illness } & \multirow[b]{2}{*}{$P$ value } \\
\hline & $\%$ & $95 \% \mathrm{Cl}$ & $\%$ & $95 \% \mathrm{Cl}$ & \\
\hline Age (mean) & 40.0 & (39.6 to 40.5 ) & 43.9 & (43.6 to 44.3 ) & $<0.001$ \\
\hline \multicolumn{6}{|l|}{ Sex } \\
\hline Female & 39.8 & (38.4 to 41.2$)$ & 57.5 & (56.6 to 58.3 ) & \multirow[t]{2}{*}{$<0.001$} \\
\hline Male & 60.2 & (58.8 to 61.6$)$ & 42.5 & (41.7 to 43.4 ) & \\
\hline \multicolumn{6}{|l|}{ Educational level } \\
\hline $0-7$ years & 35.5 & (34.1 to 37.0$)$ & 40.1 & (39.2 to 41.1 ) & \multirow[t]{2}{*}{$<0.001$} \\
\hline 8 years & 64.5 & (63.0 to 65.9$)$ & 59.9 & (58.9 to 60.8$)$ & \\
\hline \multicolumn{6}{|l|}{ Race } \\
\hline White & 47.7 & (46.3 to 49.1$)$ & 47.4 & (46.5 to 48.3 ) & \multirow[t]{4}{*}{0.043} \\
\hline Greyish/brown & 41.3 & (39.9 to 42.6$)$ & 42.2 & (41.4 to 43.1$)$ & \\
\hline Black & 9.91 & (9.1 to 10.7 ) & 8.95 & (8.4 to 9.5 ) & \\
\hline Yellow/indigene & 1.14 & (0.9 to 1.4$)$ & 1.44 & (1.2 to 1.6$)$ & \\
\hline \multicolumn{6}{|l|}{ Employment } \\
\hline Yes & 66.2 & (64.9 to 67.6$)$ & 54.9 & (54.0 to 55.8$)$ & \multirow[t]{2}{*}{0.000} \\
\hline No & 33.8 & (32.4 to 35.1 ) & 45.1 & (44.2 to 46.0$)$ & \\
\hline \multicolumn{6}{|l|}{ Self-rated health status } \\
\hline Good/very good & 68.2 & (66.9 to 69.6$)$ & 67.6 & (66.8 to 68.4 ) & \multirow[t]{2}{*}{0.424} \\
\hline Fair/poor/very poor & 31.8 & (30.4 to 33.1$)$ & 32.4 & (31.6 to 33.2 ) & \\
\hline \multicolumn{6}{|l|}{ Health insurance } \\
\hline Yes & 32.4 & (30.9 to 33.8 ) & 29.5 & $<0.001$ & (28.5 to 30.5 ) \\
\hline
\end{tabular}

Any mental health diagnosis includes hazardous drinking and ever been told by a doctor that they have OCD, depression, schizophrenia, bipolar disorder or other.

OCD, obsessive compulsive disorder.

statement (online supplementary material 1). In 2013, more than one in four (26\%; $95 \%$ CI 25.3 to 26.7) Brazilians had some form of mental illness-either met criteria for hazardous drinking or reported they had been diagnosed with some form of mental illness. Hazardous drinking was the most prevalent condition $(18.9 \%$; $95 \%$ CI 18.3 to 19.6$)$, followed by depression $(7.6 \%$; $95 \%$ CI 7.2 to 8.1). Other forms of mental illness, including bipolar disorders, schizophrenia, OCD was reported by less than $1 \%$ of participants (95\% CI 0.8 to 1.1 ). Table 1 shows demographic characteristics of the group with any mental illness compared with respondents with no mental illness. People with any mental illness were slightly younger than the general population (40 years old; $95 \%$ CI 39.6 to 40.5 )

Table 2 Smoking patterns and quit attempts by people with and without mental illness in Brazil, 2013

\begin{tabular}{|c|c|c|c|c|c|c|c|c|}
\hline & \multicolumn{2}{|c|}{ Current smoker } & \multicolumn{2}{|c|}{$\begin{array}{l}\text { Former smoker } \\
\text { (>1 year) }\end{array}$} & \multicolumn{2}{|c|}{ Ever smoker } & \multicolumn{2}{|c|}{ Quit attempt } \\
\hline & $\%$ & $95 \% \mathrm{Cl}$ & $\%$ & $95 \% \mathrm{Cl}$ & $\%$ & $95 \% \mathrm{Cl}$ & $\%$ & $95 \% \mathrm{Cl}$ \\
\hline No mental illness & 12.8 & 12.2 to 13.3 & 15.0 & 14.3 to 15.6 & 27.7 & 27.7 to 28.5 & 55.3 & 52.9 to 57.6 \\
\hline Any mental illness & 28.4 & 27.1 to 29.6 & 16.5 & 15.4 to 17.6 & 44.9 & 43.4 to 46.3 & 51.6 & 49.1 to 54.2 \\
\hline Hazardous drinker & 32.3 & 30.7 to 33.8 & 15.5 & 14.2 to 16.7 & 47.7 & 46.1 to 49.4 & 50.0 & 47.1 to 53.0 \\
\hline Depression & 20.9 & 18.9 to 22.9 & 19.9 & 17.9 to 21.9 & 40.8 & 38.3 to 43.2 & 58.8 & 53.6 to 64.1 \\
\hline Schizophrenia & 33.3 & 20.3 to 46.3 & 14.8 & 4.0 to 25.6 & 48.1 & 33.3 to 62.8 & 15.9 & 4.4 to 27.3 \\
\hline OCD & 25.3 & 13.5 to 37.1 & 9.4 & 1.9 to 16.8 & 34.7 & 21.5 to 47.8 & 22.9 & 4.5 to 41.4 \\
\hline Bipolar & 20.9 & 13.4 to 28.4 & 12.7 & 5.2 to 20.2 & 33.6 & 23.7 to 43.4 & 42.8 & 24.7 to 60.9 \\
\hline Other & 17.9 & 10.9 to 24.9 & 14.5 & 7.4 to 21.5 & 32.4 & 23.3 to 41.5 & 51.5 & 32.4 to 70.5 \\
\hline
\end{tabular}

Ever smoker is the combination of current smoker and former smoker.

OCD, obsessive compulsive disorder. 


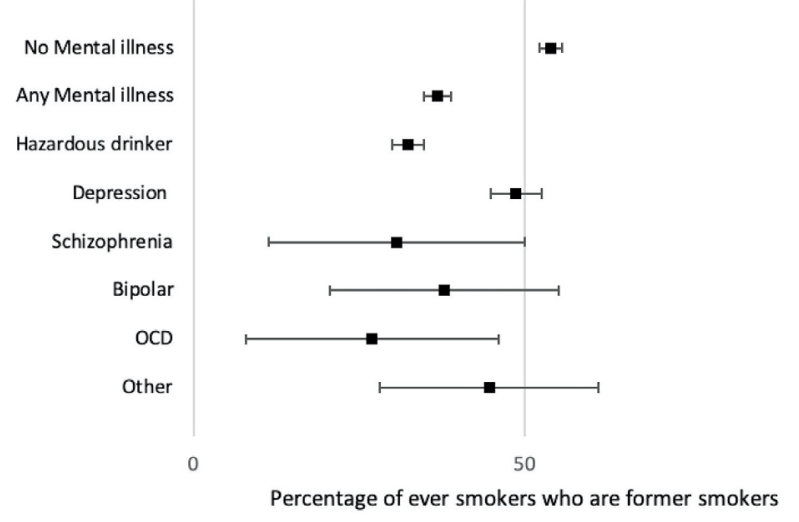

Figure 1 Quit ratio by psychiatric diagnoses. OCD, obsessive compulsive disorder.

compared with 43.9 (95\% CI 43.6 to 44.3 ) and most were males $60.2 \%$ (95\% CI 58.8 to 61.6$)$ versus $42.5 \%(95 \%$ CI 41.7 to 43.4$)$. In the same group, more people had 8 years or more of education $(64.5 \%$; (95\% CI 63.0 to 65.9$)$ vs $59.9 \%$ (95\% CI 58.9 to 60.8$)$ ), were employed $(66.2 \%$ (95\% CI 64.9 to 67.6$)$ vs $54.9 \%$ (95\% CI 54.0 to 55.8$)$ ) and had private health insurance $(32.4 \%$ (95\% CI 30.9 to 33.8 ) vs $29.5 \%$ (95\% CI 28.5 to 30.5$)$ ) compared with the no mental illness group. The results presented by mental

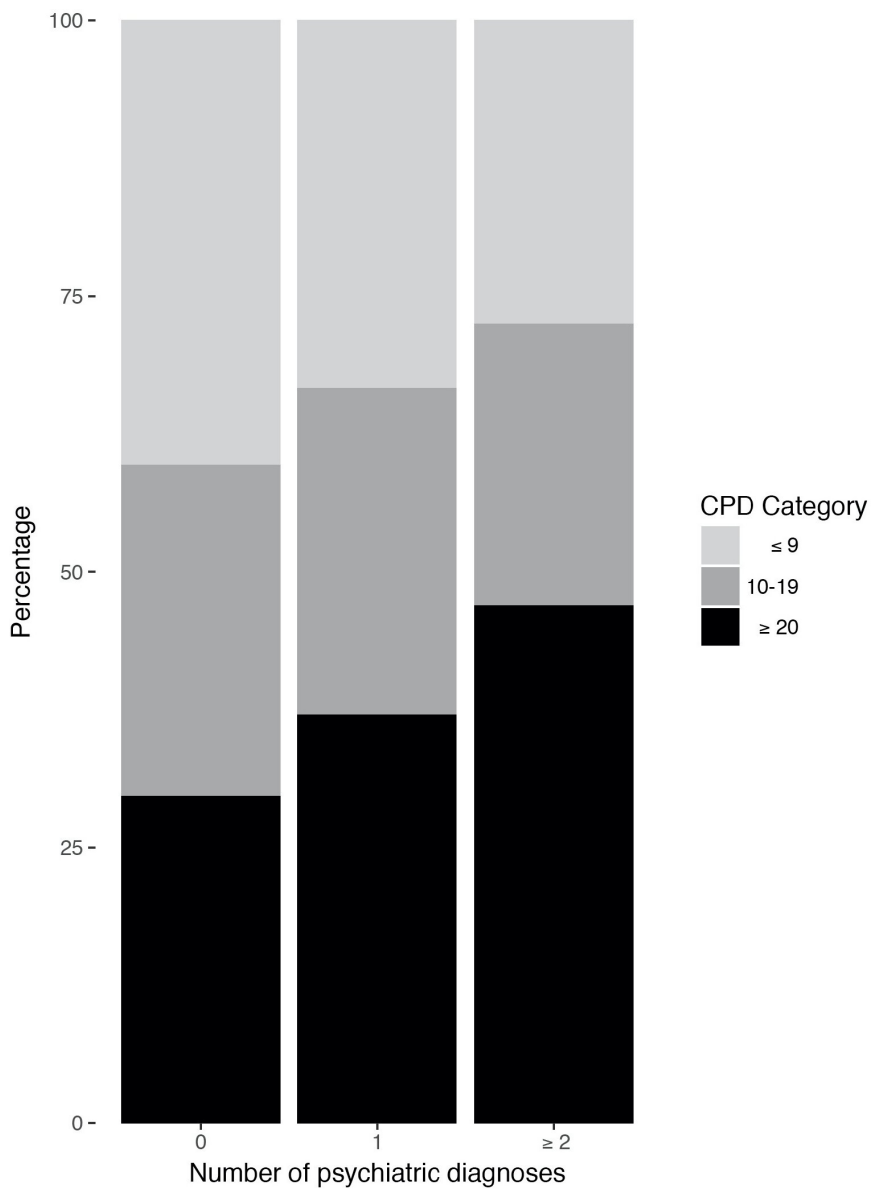

Figure 2 Cigarettes per day (CPD) and number of psychiatric diagnoses.
Table 3 Odds for smoking, quitting and attempt to quit among people with mental illness in Brazil, 2013

\begin{tabular}{|c|c|c|c|c|}
\hline & \multicolumn{4}{|c|}{ Current smoker } \\
\hline & OR & $\mathbf{P}$ & Cl & \\
\hline Any mental illness & 2.60 & $<0.001$ & 2.40 & 2.82 \\
\hline Female & 0.58 & $<0.001$ & 0.54 & 0.63 \\
\hline Age & 1.00 & 0.120 & 1.00 & 1.00 \\
\hline Education ( $>=8$ years) & 0.54 & $<0.001$ & 0.49 & 0.59 \\
\hline \multirow[t]{3}{*}{ Good/very good Health } & 0.82 & $<0.001$ & 0.75 & 0.89 \\
\hline & \multicolumn{4}{|c|}{ Former smoker } \\
\hline & OR & $\mathbf{P}$ & Cl & \\
\hline Any Mental IIIness & 0.62 & $<0.001$ & 0.55 & 0.70 \\
\hline Age & 1.04 & $<0.001$ & 1.03 & 1.04 \\
\hline Female & 1.03 & 0.580 & 0.93 & 1.14 \\
\hline Education (>=8years) & 1.07 & 0.270 & 0.95 & 1.21 \\
\hline $\begin{array}{l}\text { Medical appointment in } \\
\text { the past year }\end{array}$ & 1.51 & $<0.001$ & 1.33 & 1.71 \\
\hline $\begin{array}{l}\text { Community health } \\
\text { worker follow-up }\end{array}$ & 1.06 & 0.320 & 0.95 & 1.18 \\
\hline Private health insurance & 1.54 & $<0.001$ & 1.33 & 1.77 \\
\hline \multirow[t]{3}{*}{ Good/very good Health } & 1.06 & 0.300 & 0.95 & 1.19 \\
\hline & \multicolumn{4}{|c|}{ Attempt to quit, past year } \\
\hline & OR & $\mathbf{P}$ & $\mathrm{Cl}$ & \\
\hline Any mental illness & 0.89 & 0.100 & 0.78 & 1.02 \\
\hline $\begin{array}{l}\text { Medical appointment in } \\
\text { the past year }\end{array}$ & 1.59 & $<0.001$ & 1.37 & 1.84 \\
\hline $\begin{array}{l}\text { Community health } \\
\text { worker follow-up }\end{array}$ & 1.23 & $<0.001$ & 1.08 & 1.42 \\
\hline Good/very good Health & 0.80 & $<0.001$ & 0.69 & 0.92 \\
\hline
\end{tabular}

illness diagnoses were published as online supplementary material 2.

\section{Smoking status and quit patterns}

The prevalence of current smoking among people with any mental illness was higher than among people with no mental illness (28.4\%; $95 \%$ CI 27.1 to 29.6 vs $12.8 \%$; $95 \%$ CI 12.2 to 13.3 ) (table 2). The highest prevalence was among people with schizophrenia (33.3\%; 95\% CI 20.3 to 46.3$)$, followed by hazardous drinking $(32.3 \%$; $95 \%$ CI 30.7 to 33.8$)$, OCD $(25.3 \%$; $95 \%$ CI 13.5 to 37.1$)$, depression (20.9\%; $95 \%$ CI 18.9 to 22.9 ), bipolar disorder (20.9\%; 95\% CI 13.4 to 28.4 ) and other mental illness (17.9\%; 95\% CI 10.9 to 24.9$)$. The prevalence of ever smokers was also higher among people with any mental illness $(44.9 \%$ (95\% CI 43.4 to 46.3$)$ vs $27.7 \%$ (95\% CI 27.7 to 28.5$))$.

The percentage of people that reported they had quit for more than a year was $16.5 \%$ among people with any mental illness and $15.0 \%$ among people with no mental illness. Among people with depression, 19\%, self-reported themselves as former smokers. 
Table 4 Access to treatment and type of tobacco used by people with and without mental illness in Brazil, (2013)

\begin{tabular}{|c|c|c|c|c|c|}
\hline & \multicolumn{2}{|c|}{ Any mental illness } & \multicolumn{2}{|c|}{ No mental illness } & \multirow[b]{2}{*}{$P$ value } \\
\hline & $\%$ & $95 \% \mathrm{Cl}$ & $\%$ & $95 \% \mathrm{Cl}$ & \\
\hline Quit attempt & 51.6 & 49.1 to 54.2 & 55.3 & 52.9 to 57.6 & 0.041 \\
\hline Sought for quitting assistance & 10.7 & 8.4 to 13.1 & 7.4 & 5.5 to 9.3 & 0.024 \\
\hline $\begin{array}{l}\text { Received treatment with health } \\
\text { professional }\end{array}$ & 3.7 & 2.8 to 4.7 & 2.6 & 1.8 to 3.5 & 0.09 \\
\hline \multicolumn{6}{|l|}{ Tobacco products } \\
\hline Cigarettes & 89.9 & 88.0 to 91.7 & 81.1 & 79.2 to 83.0 & $<0.001$ \\
\hline Hand-rolled & 23.1 & 20.6 to 25.7 & 29.1 & 26.6 to 31.6 & 0.001 \\
\hline Clove & 2.5 & 1.6 to 3.3 & 1.0 & 0.5 to 1.5 & $<0.01$ \\
\hline Piper & 0.3 & 0.1 to 0.5 & 1.4 & 1.0 to 1.9 & $<0.001$ \\
\hline Cigar & 0.8 & 0.4 to 1.3 & 1.0 & 0.3 to 1.6 & 0.740 \\
\hline Hookah & 1.6 & 0.1 to 2.1 & 0.5 & 0.2 to 0.9 & 0.005 \\
\hline Other & 0.9 & 0.5 to 1.3 & 0.5 & 0.3 to 0.7 & 0.064 \\
\hline CPD (mean) & 14.1 & 13.4 to 14.8 & 12.3 & 11.8 to 12.8 & $<0.001$ \\
\hline
\end{tabular}

Quit attempts were assessed among current smokers $(n=9912)$. Quit assistance include data from current smokers who tried to quit in the past year $(n=4672)$. Tobacco products were assessed among current smokers not including those who had been quit less than a year $(n=8849)$. CPD includes only daily current smokers of manufactured cigarettes $(n=6110)$.

CPD, cigarettes per day.

The percentage of people who made a quit attempt in the past year was slightly higher among smokers with no mental illness compared with those with any mental illness. Both groups had a high percentage of quit attempts in the past year (55.3 (95\% CI 52.9 to 57.6 ) vs 51.6 (95\% CI 49.1 to 54.2), respectively). More than half of people with depression reported they had tried to quit in the past year (58.8\%; 95\% CI 53.6 to 64.1). Lower but still substantial percentages of smokers with schizophrenia $(15.9 \%$; $95 \%$ CI 4.4 to 27.3$)$ and $\mathrm{OCD}(22.9 \%, 95 \% \mathrm{CI} 4.5$ to 41.4$)$ reported they had made a quit attempt in the past year.

The quit ratio of people with no mental illness was $54.0 \%$ (95\% CI 52.3 to 55.7) and the quit ratio for people with any mental illness was $36.8 \%$ (95\% CI 34.7 to 38.8 ) (figure 1). People with depression had the highest quit ratio (48.7\%; $95 \%$ CI 44.8 to 52.6). Those with OCD had the lowest quit ratio (27\%; 95\% CI 7.9 to 46.0$)$ followed by people with schizophrenia $(30.7 \%$; $95 \%$ CI $11.4 \%$ to $50.1 \%)$. The quit ratio among respondents reporting bipolar disorder $(37.8 \%$; 95\% CI 20.6 to 55.1) and hazardous drinking $(32.4 \%, 95 \%$ CI 30.1 to 34.7$)$ were closer to the quit ratio for any mental illness.

Heaviness of smoking increased with number of psychiatric diagnoses (figure 2). Most $(70.3 \%)$ smokers with no mental illness consumed fewer than 20 cigarettes per day. Nearly half $(47.0 \%)$ of people with two or more mental illness diagnoses smoked 20 or more cigarettes per day $\left(x^{2}=4.75, \mathrm{p}=0.0009\right)$.

After adjusting for demographic variables and health status, PLWMI were still more likely to be current smokers $($ OR $(95 \%$ CI $)=2.60$ (2.40 to 2.82) ). After adjusting for demographic variables, health status, medical appointments in the past year and community health workers follow-up, participants with any mental illness were less likely to be former smokers $(\mathrm{OR}(95 \% \mathrm{CI})=0.62$ ( 0.55 to $0.70)$ ). Adjusted odds for making a quit attempt in the past year did not differ between people with and without mental illness $(\mathrm{OR}(95 \% \mathrm{CI})=0.90$ (0.78 to 1.02) ).

\section{Treatment seeking, receipt and types of tobacco used}

Few $(10.7 \%$; 95\% CI 8.4 to 13.1$)$ PLWMI and fewer $(7.4 \%$; $95 \%$ CI 5.5 to 9.3$)$ people with no mental illness sought assistance when they tried to quit smoking. Very few $(3.7 \%$ (95\% CI 2.8 to 4.7 ) vs $2.6 \%$ (95\% CI 1.8 to 3.5 ), respectively) reported that they received cessation treatment from a health professional. Most tobacco users were cigarette smokers; the average number of cigarettes smoked per day was 14.1 (95\% CI 13.4 to 14.8) for smokers with mental illness.

\section{DISCUSSION}

In Brazil, more than one in four PLWMI smoke cigarettes, roughly double the prevalence in the general population. The lifetime quit ratio among PLWMI was markedly lower than those with no mental illness (37\% vs 54\%) even though past-year odds for making a quit attempt did not differ significantly between the two groups. Across all smokers, regardless of mental status, more than half of smokers made quit attempts but very few (3\% to $4 \%$ ) received assistance in quitting. Among people with any mental illness, rates of quit attempts were highest among people with depression, who also reported greatest success in quitting (eg, the highest quit ratio). Participants with schizophrenia and OCD had the lowest quit attempts and the lowest quit ratio. 
No countries have reported national estimates of tobacco use patterns by mental health status using the GATS data. However, it is notable that in Brazil, the prevalence of tobacco use among PLWMI is lower than the prevalence of tobacco use across the entire population in many countries participating in the GATS. ${ }^{3}$ Similarly, rates of quit attempts among PLWMI in Brazil exceeded rates of quit attempts among the general population surveyed by GATS in Argentina (49\%), Panama (46\%), Nigeria (46\%) and Qatar (39.5\%). The quit ratio in Brazil among PLWMI diagnoses was higher than the quit ratio among the general population in Qatar $(26.5 \%)$ and only slightly lower than the quit ratio in the general population in Argentina (40\%), Panama $(41.5 \%)$ and Nigeria $(44.5 \%){ }^{3}$

Our findings were consistent with other studies of tobacco use among PLWMI. In general, individuals with schizophrenia and bipolar disorder consume high rates of cigarettes per day compared with people without these disorders. ${ }^{6}$ Data from the 2014 US National Survey on Drug Use and Health suggest that smoking is markedly more prevalent among heavy alcohol users, and the quit rate is lower, compared with people who do not engage in heavy drinking. ${ }^{11}$ In a nationally representative study of patients seen in federally funded health centres, US smokers with serious mental illness had higher smoking prevalence, lower quit ratios, but were just as likely to have made a past-month quit attempt, compared with smokers without mental illness. ${ }^{42}$

Brazil has a national healthcare system that provides universal access to care, and a national smoking cessation treatment programme that provides free medication and counselling. ${ }^{24}$ Tobacco treatment services, however, had uniformly low utilisation rates among tobacco users with and without mental illness. Rates of utilisation were slightly but significantly higher among PLWMI, perhaps because they may have more contact with the healthcare system, including more access to private health insurance. The vast majority had not sought or received treatment from a health professional during their past-year quit attempt, even though half of the smokers with two or more mental illnesses smoke more than 20 cigarettes per day and would be eligible for pharmacotherapy according to the Brazilian tobacco treatment guidelines. ${ }^{24}$ In practice, use of the most effective pharmacological treatments (including varenicline, bupropion and possibly dual forms of nicotine replacement therapy) remains low among patients with serious mental illness, which is potentially a reflection of general healthcare disparities between smokers with serious mental illness and the general population. ${ }^{43}$ It is not clear whether smokers with mental illness are less likely to quit because of the poor access to smoking cessation treatment or if the treatment itself is less effective for this specific population.

In Brazil, similar to other systems, smoking cessation treatment has not historically been provided in mental health institutions, nor in alcohol and drug treatment programmes. ${ }^{30} 44$ Even after receiving training in evidence-based treatment for tobacco dependence, providers in Brazil were resistant to delivering cognitive behavioural counselling and cessation medications, because most of them preferred psychodynamic therapy (which is not indicated for tobacco dependence) and they felt they were duplicating the efforts of primary care. ${ }^{30}$ Even though a federal law in Brazil prohibits smoking in collective places, healthcare institutions are explicitly exempted from the smoking ban if physicians allow patients to smoke. This appears to be most widely invoked in mental health facilities, where most smokers $(80 \%)$ reported that they smoked inside their mental health facility. ${ }^{27}$ Patients themselves could be driving these disparities; patients admitted to psychiatric hospitals are generally less supportive of a smoking ban than non-psychiatric primary care patients in Brazil. ${ }^{46}$ This holds true for other countries-for example, in the USA, the smoke-free policy that should be implemented in all mental illness institutions ${ }^{47}$ still covers only half of the mental health facilities. ${ }^{45}$

Changes in tobacco policy could lead to increased access to care. In the UK, several mental health facilities have opted to follow the National Institute of Health smoke-free policy. ${ }^{49}$ The results so far have shown increases in the numbers of patients that received smoking cessation advice from a mental healthcare provider. ${ }^{49}$

There are a number of limitations to the current study. The PNS used self-reported measures of select diagnoses to collect data on mental illness, and anxiety and mood disorders other than depression were not collected. As a result, prevalence was probably under-reported because the survey did not use a validated comprehensive measure to assess mental illness. Furthermore, the question that was used to assess mental illness would have failed to identify cases among people who had not accessed the health system (who could not have been told by a provider that they had a mental illness). Also, collecting diagnosis via self-report may have excluded those who disagreed with their physician's diagnosis. Last, people with severe mental illness were potentially less likely to participate in the survey. As a result, less than $1 \%$ of participants were identified with schizophrenia, bipolar and OCD. This led to wide CIs for prevalence estimates and limited the strength of the findings related to these mental illnesses. In addition, this question may have biassed the selection towards people with private health insurance. The public national healthcare system in Brazil is, by design, universal but funding and access to publicly-funded mental health services remains limited in many regions. Tobacco use was also self-reported and therefore subject to recall bias, under-reporting and reporting errors. Besides, the results may not generalise to those outside of the analytical sample (eg, outside of Brazil; younger than 18 years). Last, we included hazardous drinking as a mental illness instead of alcohol dependence. It probably increased the general rates of employment and education presented in table 1 . 
In conclusion, Brazilians with mental illness are twice as likely to smoke as those without mental illness. They are no less likely to try to quit, but quit attempts meet with less success. Their quit ratio is significantly lower than that of the general population. Very few Brazilians, regardless of their mental status, access medications and counselling that are purportedly available through the universal healthcare system. This suggests that the marked decrease in tobacco use rates is probably attributable not to individual treatment, but to population-level policies-including price increases, smoke-free laws and national anti-smoking campaigns. Unaided quit attempts have very low success for any smoker, but are particularly ineffective among people with mental comorbidities. ${ }^{50}$ Changing the culture of tobacco treatment in mental health facilities, encouraging PLWMI to seek treatment for tobacco dependence, and expanding utilisation of evidence-based care in all settings, might be a good place to start for Brazil to make even further inroads into tobacco use and related mortality.

Contributors EC coordinated the design, analysis and writing the manuscript. KPR participated in the design, analysis and in preparing the manuscript. EL performed the statistical analyses and participated in preparing the manuscript. $\mathrm{JH}$ performed the statistical analyses. IL participated in the design and in preparing the manuscript. All of the authors wrote the article, and they were responsible for the final content of the manuscript. All of the authors contributed to the design of the research and read, edited and approved of the final draft of the manuscript.

Funding The American Association of University Women (AAUW) international postdoctoral fellowship.

Competing interests None declared.

Patient and public involvement Patients and/or the public were not involved in the design, or conduct, or reporting or dissemination plans of this research.

Patient consent for publication Not required.

Provenance and peer review Not commissioned; externally peer reviewed.

Data availability statement Data are available in a public, open access repository. We used data from the nationally representative Brazilian National Health Survey "Pesquisa Nacional de Saúde - PNS" that is publicly available at http://asdfree. com.

Open access This is an open access article distributed in accordance with the Creative Commons Attribution Non Commercial (CC BY-NC 4.0) license, which permits others to distribute, remix, adapt, build upon this work non-commercially, and license their derivative works on different terms, provided the original work is properly cited, appropriate credit is given, any changes made indicated, and the use is non-commercial. See: http://creativecommons.org/licenses/by-nc/4.0/.

\section{ORCID iD}

Erica Cruvinel http://orcid.org/0000-0003-2778-3693

\section{REFERENCES}

$1 \mathrm{Ng} \mathrm{M}$, Freeman MK, Fleming TD, et al. Smoking prevalence and cigarette consumption in 187 countries, 1980-2012Global smoking prevalence and cigarette ConsumptionGlobal smoking prevalence and cigarette consumption. Jama 2014;311:183-92.

2 GBD 2015 Tobacco Collaborators. Smoking prevalence and attributable disease burden in 195 countries and territories, 19902015: a systematic analysis from the global burden of disease study 2015. Lancet 2017;389:1885-906.

3 Asma S, Mackay J, Song SY, et al. The GATS atlas. Atlanta, GA: CDC Foundation, 2015.

4 IBdGeE. Pesquisa Nacional de Saúde 20132014.

5 Drope J, Liber AC, Cahn Z, et al. Who's still smoking? disparities in adult cigarette smoking prevalence in the United States. CA Cancer J Clin 2018;68:106-15.
6 Cook BL, Wayne GF, Kafali EN, et al. Trends in smoking among adults with mental illness and association between mental health treatment and smoking cessation. JAMA 2014;311:172-82.

7 Jackson JG, Diaz FJ, Lopez L, et al. A combined analysis of worldwide studies demonstrates an association between bipolar disorder and tobacco smoking behaviors in adults. Bipolar Disord 2015;17:575-97.

8 Lawrence D, Mitrou F, Zubrick SR. Smoking and mental illness: results from population surveys in Australia and the United States. BMC Public Health 2009;9:285.

9 de Leon J, Diaz FJ. A meta-analysis of worldwide studies demonstrates an association between schizophrenia and tobacco smoking behaviors. Schizophr Res 2005;76:135-57.

10 Dickerson F, Schroeder J, Katsafanas E, et al. Cigarette smoking by patients with serious mental illness, 1999-2016: an increasing disparity. Psychiatr Serv 2018;69:147-53.

11 Weinberger AH, Gbedemah M, Goodwin RD. Cigarette smoking quit rates among adults with and without alcohol use disorders and heavy alcohol use, 2002-2015: a representative sample of the United States population. Drug Alcohol Depend 2017;180:204-7.

12 Lawrence D, Hancock KJ, Kisely S. The gap in life expectancy from preventable physical illness in psychiatric patients in Western Australia: retrospective analysis of population based registers. BMJ 2013;346:f2539.

13 Colton CW, Manderscheid RW. Congruencies in increased mortality rates, years of potential life lost, and causes of death among public mental health clients in eight states. Prev Chronic Dis 2006;3:A42.

14 Bandiera FC, Anteneh B, Le T, et al. Tobacco-Related mortality among persons with mental health and substance abuse problems. PLoS One 2015;10:e0120581.

15 Callaghan RC, Veldhuizen S, Jeysingh T, et al. Patterns of tobaccorelated mortality among individuals diagnosed with schizophrenia, bipolar disorder, or depression. J Psychiatr Res 2014;48:102-10.

16 Metse AP, Wiggers J, Wye P, et al. Efficacy of a universal smoking cessation intervention initiated in inpatient psychiatry and continued post-discharge: a randomised controlled trial. Aust N Z J Psychiatry 2017;51:366-81.

17 Gilbody S, Peckham E, Bailey D, et al. Smoking cessation for people with severe mental illness (SCIMITAR+): a pragmatic randomised controlled trial. Lancet Psychiatry 2019;6:379-90.

18 Evins AE, Benowitz NL, West R, et al. Neuropsychiatric safety and efficacy of varenicline, bupropion, and nicotine patch in smokers with psychotic, anxiety, and mood disorders in the eagles trial. J Clin Psychopharmacol 2019;39:108-16.

19 Castaldelli-Maia JM, Loreto AR, Guimarães-Pereira BBS, et al. Smoking cessation treatment outcomes among people with and without mental and substance use disorders: an observational realworld study. Eur Psychiatry 2018;52:22-8.

20 Prochaska JJ, Das S, Young-Wolff KC. Smoking, mental illness, and public health. Annu Rev Public Health 2017;38:165-85.

21 Taylor G, McNeill A, Girling A, et al. Change in mental health after smoking cessation: systematic review and meta-analysis. BMJ 2014;348:g1151.

22 Prochaska JJ, Delucchi K, Hall SM. A meta-analysis of smoking cessation interventions with individuals in substance abuse treatment or recovery. J Consult Clin Psychol 2004;72:1144-56.

23 Vasconcelos CMP. D.F. O sistema único de saúde / National health system. In: Akerman M, Drumond Junior M, Carvalho YM, eds. Tratado de saúde coletiva. 1. Rio de Janeiro: Hucitec;Fiocruz, 2006: 531-62.

24 Coordenação BMdSINdC-I, (CONPREV). dPeV. Abordagem e Tratamento do Fumante - Consenso 2001. Rio de Janeiro, Brazil: INCA, 2001: 38.

25 STd S, Martins MC, FRd F, et al. Combate AO Tabagismo no Brasil: a importância estratégica das ações governamentais. Ciência \& Saúde Coletiva 2014;19:539-52.

26 Ratto LRC, Menezes PR, Gulinelli A. Prevalence of tobacco use in individuals with severe mental illnesses, São Paulo, Brazil. Rev Saude Publica 2007;41:510-6.

27 Barros FCRde, Melo APS, Cournos F, et al. Cigarette smoking among psychiatric patients in Brazil. Cad Saude Publica 2014;30:1195-206.

28 Castaldelli-Maia JM, Carvalho CFC, Armentano F, et al. Outcome predictors of smoking cessation treatment provided by an addiction care unit between 2007 and 2010. Braz J Psychiatry 2013;35:338-46.

29 Castaldelli-Maia JM, Loreto AR, Carvalho CFC, et al. Retention predictors of a smoking treatment provided by a public psychosocial unit in Brazil. Int Rev Psychiatry 2014;26:515-23.

30 Castaldelli-Maia JM, da Silva NR, Campos MR, et al. Implementing evidence-based smoking cessation treatment in psychosocial care units (CAPS) in Brazil. Int J Soc Psychiatry 2017;63:669-73. 
31 PRBd S-J, MPSd F, GdA A, et al. Desenho dA amostra dA Pesquisa Nacional de Saúde 2013. Epidemiologia e Serviços de Saúde 2015;24:207-16.

32 Higgins ST, Kurti AN, Redner R, et al. Co-Occurring risk factors for current cigarette smoking in a U.S. nationally representative sample. Prev Med 2016;92:110-7.

33 Lawrence D, Fagan P, Backinger CL, et al. Cigarette smoking patterns among young adults aged 18-24 years in the United States. Nicotine Tob Res 2007;9:687-97.

34 Brown CC, Wei F. The impact of insurance gain and discussions with healthcare providers on quitting smoking. Behav Med 2018;44:160-70.

35 UNDP. Human development report 2014. sustaining human progress: reducing vulnerabilities and building resilience. New York, NY, 2014.

36 Idler EL, Benyamini Y. Self-Rated health and mortality: a review of twenty-seven community studies. J Health Soc Behav 1997;38:21-37.

37 Szwarcwald CL, Souza-Júnior PRBde, Esteves MAP, et al. SocioDemographic determinants of self-rated health in Brazil. Cad Saude Publica 2005;21:S54-64.

38 Babor F, de la Fuente JR, Saunders J, et al. The alcohol use disorders identification test (audit). guidelines for use in primary health care. Geneva, Switzerland: World Health Organization, 1992.

39 Team RDC. A language and environment for statistical computing. Vienna, Austria: R Foundation for Statistical Computing, 2018.

40 Lumley T. Survey: analysis of complex survey samples 2019.

41 Jamal A, Phillips E, Gentzke AS, et al. Current Cigarette Smoking Among Adults - United States, 2016. MMWR Morb Mortal Wkly Rep 2018;67:53-9.
42 Kalkhoran S, Thorndike AN, Rigotti NA, et al. Cigarette smoking and Quitting-Related factors among US adult health center patients with serious mental illness. J Gen Intern Med 2019;34:986-91.

43 Evins AE, Cather C, Daumit GL. Smoking cessation in people with serious mental illness. Lancet Psychiatry 2019;6:563-4.

44 Richter KP, Hunt JJ, Cupertino AP, et al. Commitment and capacity for providing evidence-based tobacco treatment in US drug treatment facilities. Subst Abus 2017;38:35-9.

45 Marynak K, VanFrank B, Tetlow S, et al. Tobacco Cessation Interventions and Smoke-Free Policies in Mental Health and Substance Abuse Treatment Facilities - United States, 2016. MMWR Morb Mortal Wkly Rep 2018;67:519-23.

46 de Oliveira RM, Santos JLF, Furegato ARF. Opinions of hospitalized patients with mental disorders and patients in basic health units in Brazil regarding tobacco smoking. Issues Ment Health Nurs 2018;39:1-8.

47 van der Eijk Y. The convention on the rights of persons with disabilities as a tobacco control tool in the mental health setting. Tob Control 2018;27:637-42 https://www.un.org/development/desa/ disabilities/convention-on-the-rights-of-persons-with-disabilities.html

48 . smoking cessation in secondary care: acute, maternity and mental health services. Available: https://www.nice.org.uk/guidance/ph48

49 Huddlestone L, Sohal H, Paul C, et al. Complete smokefree policies in mental health inpatient settings: results from a mixed-methods evaluation before and after implementing national guidance. BMC Health Serv Res 2018:18:542.

50 Tsoi DT, Porwal M, Webster AC. Interventions for smoking cessation and reduction in individuals with schizophrenia. Cochrane Database Syst Rev 2013;2:Cd007253. 